\section{A Micro Ultrafiltration Apparatus}

\section{R. H. WILKINSON}

From the Department of Chemical Pathology, The Hospital for Sick Children, Great Ormond Street, London

(RECEIVED FOR PUBLICATION FEBRUARY 26, 1960)

It is a great advantage to be able to obtain proteinfree ultrafiltrate in a simple manner from plasma or other body fluids for micro analysis. Dilution of the substance to be analysed is avoided. Errors due to dilution, protein precipitation, and transfer are minimized. Ultrafiltration on a micro scale is used in this laboratory also for paper chromatography of sugars, plasma calcium fractions, and for body space determinations. Plasma ultrafiltrable calcium levels using this apparatus have been compared with the clinical picture in neonatal tetany by Craig (1958) and by Craig and Buchanan (1958). The estimation of plasma water and the calculation of a Donnan equilibrium in body space determinations are avoided when ultrafiltrate is used.

Two methods are available for 3-5 ml. volumes of plasma. In the first method the fluid is driven through a membrane (which is impermeable to protein) by centrifuging (Toribara, Terepka, and Dewey, 1957). Using a laboratory centrifuge, kept at $37^{\circ} \mathrm{C}$., these workers obtained $0.5 \mathrm{ml}$. of ultrafiltrate from $3 \mathrm{ml}$. of plasma in three hours. This fraction has been found to decrease as the method is scaled down to volumes of 0.2 to $1.0 \mathrm{ml}$., since losses play a greater part. In the second group of methods the ultrafiltrate is obtained by maintaining a pressure differential across a membrane. Where $p \mathbf{H}$ and gas tensions are important, e.g., in measuring the ultrafiltrable calcium levels in plasma, it is preferable to use the positive pressure of a column of mercury on the plasma side of the membrane. Lavietes (1937) designed an apparatus for this purpose. However, 3-5 $\mathrm{ml}$. of plasma was necessary. The two glass hemispheres were fragile and they were difficult to clamp into position. The following apparatus has been designed for 0.2 to $1.0 \mathrm{ml}$. volumes of plasma or blood. These volumes can be obtained with ease by skin puncture in infants and children (Wilkinson, 1960). The apparatus has been in use for five years satisfactorily. The actual filling of the apparatus is very simple and takes two minutes. Filtration proceeds overnight without attention at any desired temperature. At $20^{\circ} \mathrm{C}$. and $37^{\circ} \mathrm{C}$., $0.5 \mathrm{ml}$. of ultrafiltrate, and at $4^{\circ} \mathrm{C}$., $0.3 \mathrm{ml}$. of ultrafiltrate, was obtained from $1.0 \mathrm{ml}$. of plasma in eight hours through a membrane of $80 \mathrm{~mm}^{2}$ area using a pressure of 760 $\mathrm{mm}$. of mercury.

\section{Construction}

The glass parts are blown from two flanged tubes $(10 \mathrm{~mm}$. bore, $30 \mathrm{~mm}$. flange diameter) and a diagonalbore spring-loaded tap. The approximate dimensions are indicated in Figs. 1 and 2. The clamp is made from brass rod and strip (Fig. 3). The membrane is cellophane P.T. 600.* The mercury is purified carefully in the normal way, but traces of calcium must be removed with strongly alkaline E.D.T.A. when determining ultrafiltrable calcium levels in plasma. The complete apparatus consists of a glass mercury reservoir connected by elastic P.V.C. tubing to the filtration chamber. A screw tunnel clamp is placed on the tubing near to this. The cellophane membrane is held securely between the glass flanges which are compressed by the brass clamp. The flanges are protected by thick rubber collars.

(1) Plasma Ultrafiltrate Technique for Calcium.Blood obtained by skin or vein puncture is delivered below liquid paraffin with the minimum of contact with air. Heparin is used as an anticoagulant. The tube is capped and centrifuged. The plasma is removed from the cells and stored in a refrigerator for not longer than 24 hours at $-10^{\circ} \mathrm{C}$. The glass apparatus is cleaned in strong alcoholic potassium hydroxide, washed with glass-distilled water, and dried in an oven. The tap and opposing surfaces of the flanges are smeared lightly with high vacuum silicone grease. A small square of cellophane which has been soaked in distilled water for one to three hours is blotted carefully between ashless filter paper and placed over the flange and opening of the lower compartment. The upper compartment is placed gently over this, flange to flange, and the apparatus is fitted into the brass clamp. The nuts are tightened so that the plates compress the flanges firmly and equally. The plastic tubing is attached to the side tube of the apparatus, and the funnel and tubing are filled with mercury. The brass clamp is rotated so that the glass outlet tube points upwards and the tunnel clamp in the plastic tubing is opened. The glass tap is opened gently and mercury is allowed to fill the compartment and the capillary outlet tube to its tip. The tap is closed and the clamp rotated so that the outlet tube once more points downwards. Mercury is placed in the upper glass compartment to a depth of 2 to $3 \mathrm{~mm}$. to facilitate removal of the ultrafiltrate. The upper opening of the compartment is closed with a rubber policeman. The plasma is equilibrated for three minutes with "alveolar" air which has been passed over wet glass beads. The small tube containing the plasma is arranged so that the outlet tube of the apparatus passes to the bottom of the tube. The mercury funnel is lowered below the level of the apparatus and the glass tap is opened gently so that plasma is drawn up into the lower compartment. The tap is closed and the mercury funnel is raised to a height of $76 \mathrm{~cm}$. above the apparatus. The glass tap is opened gently to expel the plasma in the

*British Cellophane Ltd., 9, Henrietta Place, London, W.1. 
Fig. 3.-Exploded view of apparatus (two-thirds actual size).
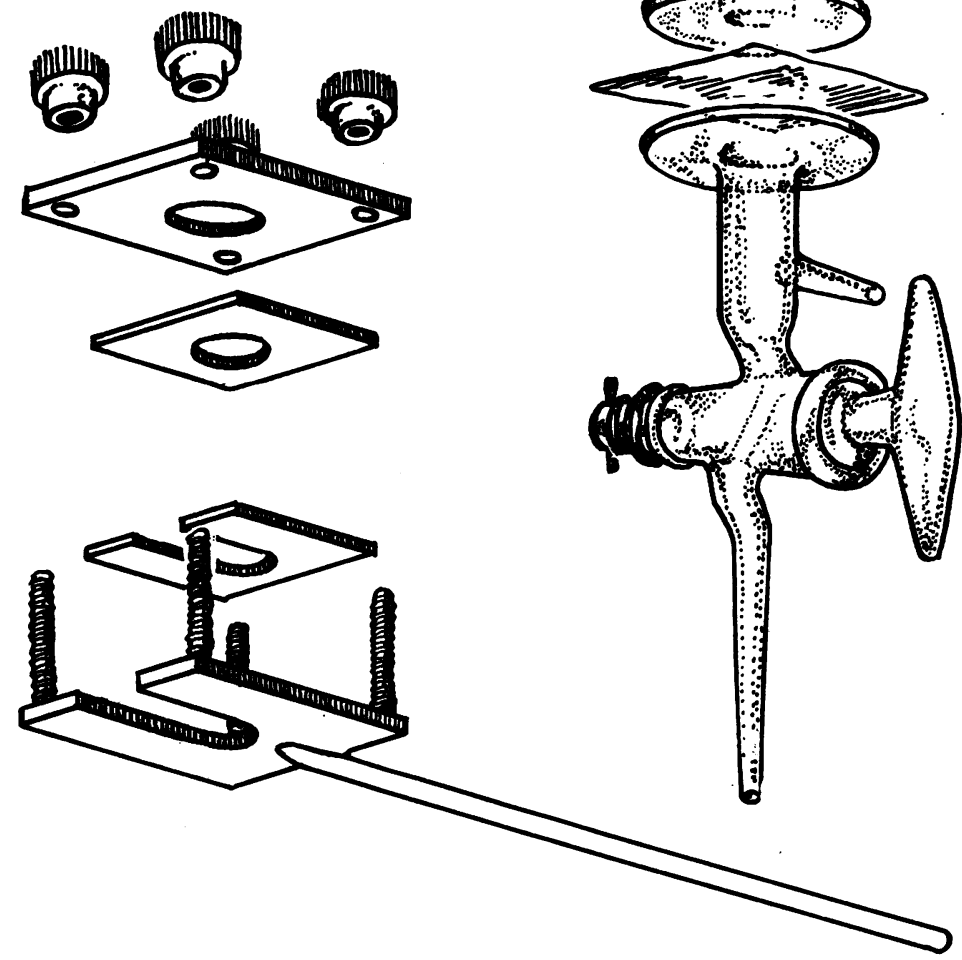

micro analyses where the concentration of a substance must be kept as high as possible. Heparinized blood is collected and centrifuged in the usual manner. The apparatus is assembled and filled with mercury. Mercury is placed on the upper surface of the membrane. Whole blood (preserved with fluoride) has been ultrafiltered, the ultrafiltrate desalted with an ion exchange resin, and the sugars present identified and their concentration measured approximately by paper chromatography. Other plasma substances, whose concentration is not affected by prolonged contact with red cells, may be estimated after ultrafiltration of whole blood. After filtration, the clear fluid may be measured with a constriction pipette, and frequently a colorimetric procedure can be carried out directly in a single tube or cuvette. This makes a significant contribution to the accuracy of a method since errors inherent in plasma protein precipitation and transfer pipettings are avoided.

\section{Summary}

An apparatus is described for ultrafiltering volumes of 0.2 to

capillary tube back into the specimen tube. The tap is then closed again. When using $1.0 \mathrm{ml}$. of plasma, $760 \mathrm{~mm}$. Hg pressure, and a membrane of $80 \mathrm{~mm}^{2}$ area, ultrafiltration at $20^{\circ} \mathrm{C}$. and $37^{\circ} \mathrm{C}$. proceeds approximately linearly until $0.5 \mathrm{ml}$. of filtrate is obtained in eight hours. A total of 0.65 to $0.7 \mathrm{ml}$. is obtained in 15 hours (overnight). At $0^{\circ} \mathrm{C}$. ultrafiltration proceeds linearly for 12 hours until $0.5 \mathrm{ml}$. of ultrafiltrate is obtained and 0.65 to $0.7 \mathrm{ml}$. requires 24 hours. It is convenient to allow ultrafiltration to proceed overnight. The ultrafiltrate is removed from the upper compartment by means of a fine Pasteur pipette and may be analysed for calcium (or magnesium) using $0.2 \mathrm{ml}$. (Wilkinson, 1957). The $p \mathrm{H}$ of the ultrafiltrate is checked (after equilibration) with a B.D.H. capillator (phenol red). Protein is tested for with sulphosalicylic acid.

(2) Ultrafiltration Not Needing pH Control.-Ultrafiltrate may be prepared for the chromatography of sugars, amino-acids, organic acids, etc.; for determining body space volumes, and in general for
$1.0 \mathrm{ml}$. of body fluids under strictly anaerobic conditions or with $p \mathrm{H}$ control if necessary. The operation is simple, dependable, and has been in routine use for five years.

I should like to thank the Department of Medical Illustration for Figs. 1, 2, and 3 ; Messrs. Laboratory Glassblowers Co. Ltd., Valley Works, Lane End Road, Sands, High Wycombe, for supplying the glass parts to my design so ably; and D. J. Perry \& Co. Ltd., 7, Avon Trading Estate, Avonmore Road, London, W.14, for supplying the grade of cellophane.

\section{REFERENCES}

Craig, W. S. (1958). Pediatrics, 22, 297.

Crend Buildh., 33, 505. Lavietes, P. H. (1937). J. biol. Chem., 120, 267.

Toribara, T. Y., Terepka, A. R., and Dewey, P. A. (1957). J. clin. Invest., $36,738$.

Wilkinson, R. H. (1957). J. clin. Path., 10, 126. (1960). Chemical Micromethods in Clinical Medicine. Charles C. Thomas, Springfield, Illinois. 